\title{
Front Matter: Volume 7281
}

, "Front Matter: Volume 7281," Proc. SPIE 7281, 4th International Symposium on Advanced Optical Manufacturing and Testing Technologies: Large Mirrors and Telescopes, 728101 (20 May 2009); doi: 10.1117/12.834926

SPIE Event: AOMATT 2008 - 4th International Symposium on Advanced Optical Manufacturing, 2008, Chengdu, Chengdu, China 


\title{
PROCEEDINGS OF SPIE
}

4th International Symposium on Advanced Optical Manufacturing and Testing Technologies Large Mirrors and Telescopes

\author{
Wenhan Jiang \\ Roland Geyl \\ Myung K. Cho \\ Fan Wu \\ Editors
}

\section{9-21 November 2008 Chengdu, China}

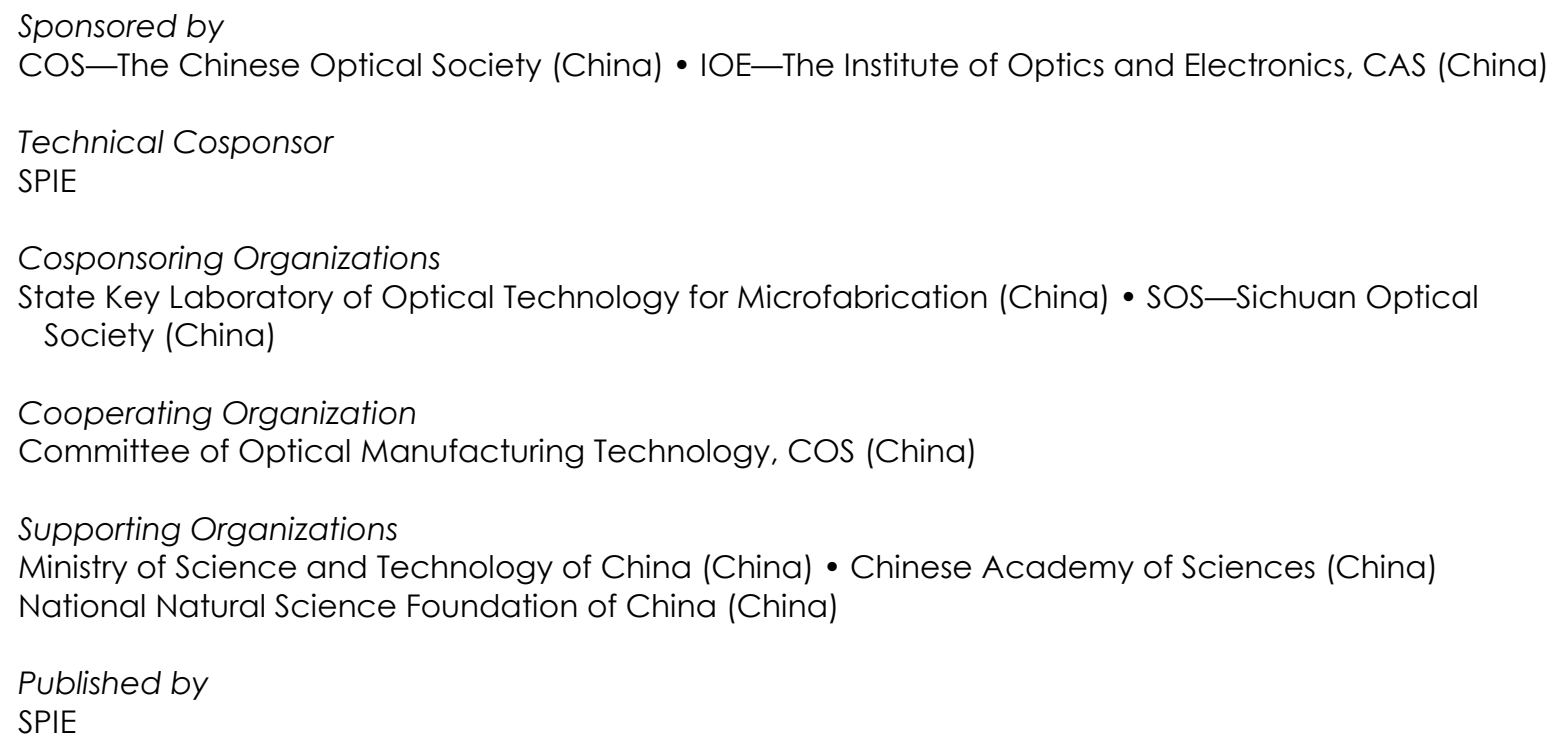

Volume 7281 
The papers included in this volume were part of the technical conference cited on the cover and title page. Papers were selected and subject to review by the editors and conference program committee. Some conference presentations may not be available for publication. The papers published in these proceedings reflect the work and thoughts of the authors and are published herein as submitted. The publisher is not responsible for the validity of the information or for any outcomes resulting from reliance thereon.

Please use the following format to cite material from this book:

Author(s), "Title of Paper," in 4th International Symposium on Advanced Optical Manufacturing and Testing Technologies: Large Mirrors and Telescopes, edited by Wenhan Jiang, Roland Geyl, Myung K. Cho, Fan WU, Proceedings of SPIE Vol. 7281 (SPIE, Bellingham, WA, 2009) Article CID Number.

ISSN 0277-786X

ISBN 9780819475411

Published by

SPIE

P.O. Box 10, Bellingham, Washington $98227-0010$ USA

Telephone +1 3606763290 (Pacific Time) · Fax +1 3606471445

SPIE.org

Copyright (C) 2009, Society of Photo-Optical Instrumentation Engineers

Copying of material in this book for internal or personal use, or for the internal or personal use of specific clients, beyond the fair use provisions granted by the U.S. Copyright Law is authorized by SPIE subject to payment of copying fees. The Transactional Reporting Service base fee for this volume is $\$ 18.00$ per article (or portion thereof), which should be paid directly to the Copyright Clearance Center (CCC), 222 Rosewood Drive, Danvers, MA 01923. Payment may also be made electronically through CCC Online at copyright.com. Other copying for republication, resale, advertising or promotion, or any form of systematic or multiple reproduction of any material in this book is prohibited except with permission in writing from the publisher. The CCC fee code is 0277-786X/09/\$18.00.

Printed in the United States of America.

Publication of record for individual papers is online in the SPIE Digital Library.

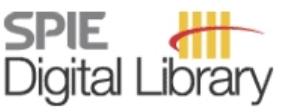

SPIEDigitalLibrary.org

Paper Numbering: Proceedings of SPIE follow an e-First publication model, with papers published first online and then in print and on CD-ROM. Papers are published as they are submitted and meet publication criteria. A unique, consistent, permanent citation identifier (CID) number is assigned to each article at the time of the first publication. Utilization of CIDs allows articles to be fully citable as soon they are published online, and connects the same identifier to all online, print, and electronic versions of the publication. SPIE uses a six-digit CID article numbering system in which:

- The first four digits correspond to the SPIE volume number.

- The last two digits indicate publication order within the volume using a Base 36 numbering system employing both numerals and letters. These two-number sets start with 00, 01, 02, 03, 04 , 05, 06, 07, 08, 09, OA, OB ... 0Z, followed by 10-1Z, 20-2Z, etc.

The CID number appears on each page of the manuscript. The complete citation is used on the first page, and an abbreviated version on subsequent pages. Numbers in the index correspond to the last two digits of the six-digit CID number. 


\title{
Contents
}

\author{
vii Conference Committee \\ ix Symposium Committees \\ xi Introduction
}

\section{PLENARY SESSION}

728102 Evolution of wavelength shrinkage in lithography [7281-01]

M. Kameyama, Nikon Corp. (Japan); M. McCallum, Nikon Precision Europe GmbH (United Kingdom); S. Owa, Nikon Corp. (Japan)

\section{SESSION 1-1}

728103 Four decades of ZERODUR mirror substrates for astronomy [7281-02]

T. Döhring, R. Jedamzik, T. Westerhoff, P. Hartmann, SCHOTT AG (Germany)

728104 Study on the surface of large-aperture optical elements in frequency domain [7281-03]

S. Li, R. Zhang, Sichuan Univ. (China)

728105 Novel method of phasing segmented mirrors [7281-04]

Q. Zhu, S. Wang, G. Cao, Beijing Institute of Technology (China)

728106 Influence of optical surface error on scattering loss of optical mirror [7281-05]

D. Wu, Y. Dai, G. Wang, National Univ. of Defense Technology (China)

728107 Control system for multi-motor friction drive of a large-scale optical telescope [7281-06] Y. Mao, Institute of Optics and Electronics (China) and Graduate School of the Chinese Academy of Sciences (China); J.-G. Ma, Q. Bao, Institute of Optics and Electronics (China); S. Yang, Southwest Univ. (China)

728108 FEM analysis and experiment study of an ultrathin active mirror [7281-07]

Y. Ni, P. Guo, Q. Huang, J. Yu, Soochow Univ. (China)

728109 Subaperture stitching interferometer for large optics [7281-08]

S. Zeng, Y. Dai, S. Chen, National Univ. of Defense Technology (China)

7281 OA Figure analysis and adjustment of a large aperture reflector [7281-09]

X. L. Chen, N. J. Ruan, J. Ma, Y. Su, Beijing Institute of Space Mechanics and Electricity (China) 
$7281 \mathrm{OB}$ Analysis of the deforming and moving feature when using stressed lap on both convex and concave hyperboloids [7281-10]

B. Gao, Nanjing Institute of Astronomical Optics \& Technology (China); F. Wu, Institute of Optics and Electronics (China)

7281 OC Decoupling control for position error and surface error of segmented primary mirror [7281-11]

B. Dong, X. YU, X. Zhang, X. Wang, Beijing Institute of Technology (China)

7281 OD Optimizing attaching area in an ultrathin active mirror system [7281-12]

B. Xie, Y. Ni, Soochow Univ. (China)

$7281 \mathrm{OE}$ Observer-based higher order sliding mode control for large optical astronomical telescopes [7281-13]

W. Zhou, X. Ye, W. Guo, Nanjing Univ. of Information Science \& Technology (China); Z. WU, Graduate School of the Chinese Academy of Sciences (China)

7281 OF Acceleration feedback control for low velocity friction in a servo control system [7281-14] T. Tang, Institute of Optics and Electronics (China) and Graduate School of the Chinese Academy of Sciences (China); Y. Huang, C. Fu, J. Ma, Institute of Optics and Electronics (China)

7281 OG Aberration analysis for development of a large-aperture reflector by finite element [7281-15]

Y. Peng, Nanjing Institute of Astronomical Optics and Technology (China) and Graduate School of the Chinese Academy of Sciences (China); L. Yuan, Nanjing Institute of Astronomical Optics and Technology (China)

$7281 \mathrm{OH}$ Analysis of piston error of an optical sparse-aperture imaging system [7281-16] J. Zhao, D. Wang, Z. Zhou, Y. Wan, Z. Jiang, S. Tao, Beijing Univ. of Technology (China)

7281 ol Forward kinematic analysis on the parallel supporting structure of large opto-electronic equipment [7281-17]

G. Cheng, S.-R. Ge, China Univ. of Mining and Technology (China); Y.-J. Wan, Institute of Optics and Electronics (China)

\section{POSTER SESSION}

7281 0J Research on the structure and dynamic characteristics of a fast-steering mirror [7281-18] J. Zhou, H. Yin, East China Jiaotong Univ. (China); Y. Wang, Beijing Institute of Space Mechanics and Electricity (China)

7281 OK Numerical simulation of airflow in a $2 m$ telescope [7281-19] F. Zhao, Beijing Technology and Business Univ. (China); P. Wang, Beijing Institute of Technology (China); Y. Gong, L. Zhang, C. Meng, J. Lin, Beijing Technology and Business Univ. (China) 
$7281 \mathrm{OL}$ The mathematical analysis when using four-bar linkage structure to off-axis segment [7281-20]

B. Gao, Nanjing Institute of Astronomical Optics \& Technology (China); F. Wu, Institute of Optics and Electronics (China)

$72810 \mathrm{M}$ Optical design of a reflecting telescope with a large field [7281-21]

D. Gong, Changchun Institute of Optics, Fine Mechanics and Physics (China) and Graduate School of the Chinese Academy of Sciences (China); H. Wang, T. Tian, Changchun Institute of Optics, Fine Mechanics and Physics (China); J. Yuan, Changchun Office of Shenyang Army Branch (China)

$7281 \mathrm{ON} \quad$ Study on the limiting ability of shaping aspheric surfaces by FEM [7281-22] C. Zeng, J. Yu, Soochow Univ. (China)

$728100 \quad$ Fabrication and testing of a $600 \mathrm{~mm}$ diameter brazing SiC mirror [7281-23]

B. Zhang, X. Wang, Changchun Institute of Optics, Fine Mechanics and Physics (China) and Graduate School of the Chinese Academy of Sciences (China); X. K. Wang, Z. Zhang, $X$. Zhang, Changchun Institute of Optics, Fine Mechanics and Physics (China)

7281 OP Method for detection of primary mirror figure deformation in space [7281-24]

X. Wang, H. Mao, D. Zhao, Beijing Institute of Technology (China)

$7281 \mathrm{OQ}$ Orientation error analysis of an alt-alt photoelectric telescope [7281-25]

$X$. Han, Changchun Institute of Optics, Fine Mechanics and Physics (China) and Graduate School of the Chinese Academy of Sciences (China); J. Zhang, J. Zhao, Changchun Institute of Optics, Fine Mechanics and Physics (China); Y. Zhao, Changchun Institute of Optics, Fine Mechanics and Physics (China) and Graduate School of the Chinese Academy of Sciences (China); X. Wu, Z. Wang, Changchun Institute of Optics, Fine Mechanics and Physics (China)

7281 OR Diffraction effects on image quality of a segmented mirror with quasi-annulus sector [7281-26]

Y. Wen, J. Yan, B. Wang, M. Xiao, Beijing Institute of Technology (China)

7281 OS Hybrid algorithm in phase diversity wavefront sensing [7281-27]

X. Wang, D. Zhao, H. Mao, X. Wang, Beijing Institute of Technology (China)

7281 OT Application of adaptive optics to a space-ground large deployable optics system [7281-28] X. Zhang, X. Yu, J. Yan, B. Dong, Y. Huang, X. Wang, Beijing Institute of Technology (China)

7281 OU Real-time orbit prediction in a large telescope system [7281-29]

S. Yang, Southwest Univ. (China); Y. Mao, Institute of Optics and Electronics (China) and Graduate School of the Chinese Academy of Sciences (China); J. Ma, Institute of Optics and Electronics (China)

7281 OV Inverse kinematic analysis of parallel supporting structure based on Rodrigues parameters [7281-30]

G. Cheng, S.-R. Ge, China Univ. of Mining and Technology (China); Y.-J. Wan, Institute of Optics and Electronics (China) 
7281 OW Research on cooling technology for a large-aperture solar telescope's primary mirror [7281-31]

Q. Wang, Nanjing Institute of Astronomical Optics and Technology (China) and Graduate School of the Chinese Academy of Sciences (China); H. Zhang, Nanjing Institute of Astronomical Optics and Technology (China)

$72810 X \quad$ Far-infrared Fizeau interferometer for a large aspheric mirror [7281-32]

Y. Wu, Y. Zhang, Institute of Optics and Electronics (China)

Author Index 


\title{
Conference Committee
}

\author{
Conference Chairs \\ Wenhan Jiang, Chinese Academy of Engineering (China) \\ Roland Geyl, Sagem SA (France) \\ Myung K. Cho, National Optical Astronomy Observatory \\ (United States) \\ Fan Wu, Institute of Optics and Electronics, CAS (China)
}

Program Committee

James H. Burge, College of Optical Sciences, The University of Arizona (United States)

Bernard Delabre, European Southern Observatory (Germany)

Eric Ruch, Sagem SA (France)

Magomed A. Abdulkadyrov, Lytkarino Optical Glass Factory (Russian Federation)

Matt Johns, Carnegie Observatories (United States)

Hans J. Kärcher, MT Mechatronics GmbH (Germany)

Jingchi Yu, Suzhou University (China)

Sung-Kie Youn, KAIST_Korea Advanced Institute of Science and Technology (Korea, Republic of)

Bilie Gao, Nanjing Institute of Astronomical Optics \& Technology, CAS (China)

Session Chairs

Session 1-1

Fan Wu, Institute of Optics and Electronics, CAS (China)

Session 1-2

Bin Fan, Institute of Optics and Electronics, CAS (China) 
Downloaded From: https://www.spiedigitallibrary.org/conference-proceedings-of-spie on 26 Apr 2023

Terms of Use: https://www.spiedigitallibrary.org/terms-of-use 


\section{Symposium Committees}

Honorary Chair

Daheng Wang, Chinese Academy of Sciences (China) and Chinese Academy of Engineering (China)

Symposium General Chair

Bingkun Zhou, Chinese Optical Society (China) and Chinese Academy of Sciences (China)

Symposium General Cochairs

James C. Wyant, College of Optical Sciences, The University of Arizona (United States)

Jianlin Cao, Ministry of Science and Technology of China (China)

Yudong Zhang, Institute of Optics and Electronics, CAS (China)

Organizing Committee

Yudong Zhang, Chair, Institute of Optics and Electronics, CAS (China)

Jinghua Cao, Cochair, Bureau of International Cooperation, CAS (China)

Guoqiang Ni, Cochair, Chinese Optical Society (China)

Jos Benschop, ASML (Netherlands)

John M. Schoen, University of Rochester (United States)

Edgar Bader, Carl Zeiss SMT AG (Germany)

Li Yang, Committee of Optical Manufacturing Technology, COS (China)

Jinxue Wang, SPIE

Eric Ruch, REOSC Optics, SAGEM (France)

James H. Burge, College of Optical Sciences, The University of Arizona (United States)

David D. Walker, University College London (United Kingdom)

Yoshiharu Namba, Chubu University (Japan)

Hexin Wang, Carl Zeiss Jena AG (Germany)

Masaomi Kameyama, Nikon Corporation (Japan)

Fan Wu, Institute of Optics and Electronics, CAS (China)

Rongbin Li, Hong Kong Polytechnic University (Hong Kong, China)

Tadashi Hatano, Tohoku University (Japan)

Jingzhen Li, Shenzhen University (China)

Mike DeMarco, QED Technologies (United States)

James R. Torley, University of Colorado at Colorado Springs

(United States)

Xiaoping Li, Shanghai Micro-Electronic Equipment Company, Ltd. (China)

Robert Smythe, ZYGO Corporation (United States)

Richard Freeman, ZEEKO Ltd. (United Kingtom)

Gavin F. Chapman, Moore Precision Tools (United States) 
Program Committee

Hu Yang, Chair, Institute of Optics and Electronics, CAS (China)

Yuwen Qin, Cochair, Natural Science Foundation of China (China)

Sen Han, Cochair, Veeco Metrology Inc. (United States)

Myung K. Cho, Cochair, National Optical Astronomy Observatory (United States)

Bernard Delabre, European Southern Observatory (Germany)

Huadong Yu, Changchun University of Science and Technology (China)

Magomed A. Abdulkadyrov, Lytkarino Optical Glass Factory (Russian Federation)

Jose M. Sasian, College of Optical Sciences, The University Arizona (United States)

Ming Liu, Institute of Microelectronics, CAS (China)

Qiming Xin, Beijing Institute of Technology (China)

Wei Li, Chengdu Fine Precision Optical Engineering Research Center (China)

Paul Kloceck, ELCAN Optical Technologies (United States)

Jingchi Yu, Suzhou University (China)

Xuemin Cheng, Tsinghua University (China)

Xuejun Zhang, Changchun Institute of Optics, Fine Mechanics and Physics, CAS (China)

Mary G. Turner, InfoTek Information Systems (United States)

Changyuan Han, Optical Testing Technology Committee, COS (China)

Masahide Katsuki, Toshiba Machine Company, Ltd. (Japan)

Ying Chun Liang, Harbin Institute of Technology (China)

Matthias Pfaff, OptoTech Optikmaschinen GmbH (Germany)

Michael Sander, Satisloh GmbH (Germany)

Thomas Danger, Schneider GmbH \& Company KG (Germany)

Michael Conroy, Taylor Hobson Ltd. (United Kingdom)

Secretary General of the Symposium

Li Yang, Committee of Optical Manufacturing Technology, COS (China) Jinxue Wang, SPIE (United States) 


\section{Introduction}

Optical manufacturing technology has achieved tremendous progress, especially during the last 20 years both in China and abroad. To meet the demand of the development in this area, AOMATT-International Symposium on Advanced Optical Manufacturing and Testing Technology has been held four times from 2000 to 2008. The 4th International Symposium on Advanced Optical Manufacturing and Testing Technology (AOMATTO8) was held at Wang Jiang Hotel in Chengdu, China, 19-21 November 2008. A total of 381 papers have been selected for publication in the Proceedings of SPIE volumes 7281, 7282, 7283 and 7284, corresponding to the four conferences of AOMATT08: Large Mirrors and Telescopes; Advanced Optical Manufacturing Technologies; Optical Test and Measurement Technology and Equipment; and Design, Manufacturing, and Testing of Micro- and Nano-Optical Devices and Systems. We have faced many challenges during the organization of AOMATT08. They include the big Sichuan Wenchuan earthquake on 12 May 2008, the worldwide financial crisis, and the deepening recession in many countries around the world. These challenges and difficulties have negatively impacted the number of papers and attendees for AOMATT08. The number of accepted papers decreased from 485 for AOMATT07 to 381 for AOMATT08. However, conference quality has continued to improve. Based on comments from authors and attendees, significant improvements have been made in conference organization, the opening ceremony, quality of the plenary presentation, oral presentations, workshops, and the closing ceremony, etc. A more important fact is the continued improvement in the quality of the papers published in the Proceedings of SPIE. Many papers report cutting-edge research and development; more authors are from famous universities, research institutions, and leading enterprises around the world. Authors and attendees had the opportunity to exchange ideas and learn from each other at the conference.

We are delighted that each AOMATT symposium is more successful than the previous one. It has become a well-established symposium covering advanced optical manufacturing and testing technologies, and has attracted a loyal following in academy and industries around the world. Our goal is to develop AOMATT into a must-attend international symposium for the optical manufacturing and testing community. We would like to express our sincere appreciation to COS-The Chinese Optical Society, IOE-Institute of Optics and Electronics, Chinese Academy of Sciences, and to SPIE for sponsoring AOMATT08. We want to thank authors and attendees for attending the symposium and sharing their research with their colleagues around the world. We especially thank IOE and Dr. Yudong Zhang, President of IOE, for hosting AOMATTO8 and the tremendous hospitality during the conference.

The world is in the middle of significant financial and economic crisis. Crisis often brings difficulties and opportunities at the same time. Many countries have 
announced economic stimulus measures. The Chinese government has promised 600 billion Yuan RMB to six key national projects. Several projects are closely related to optical manufacturing and testing technology and equipments and represent opportunities for researchers and enterprises around the world. New discoveries and products will emerge as a result. We are looking forward to seeing you all at the AOMATT 2010 in China, please watch the SPIE and IOE websites for call for papers and exact time and locations.

Li Yang

Secretary General, AOMATT 2008

Chairman, Committee on Optical Manufacturing Technology (COMT), COS 